\title{
AS ESCOLHAS DE AUERBACH: UMA QUESTÃO DE REALIDADE
}

\author{
Diego Moreira ${ }^{*}$ \\ Universidade Federal de Santa Catarina
}

Resumo: O presente artigo visa discutir alguns dos conceitos propostos pelo filólogo alemão Erich Auerbach, com foco para sua obra Mimesis: a representação da realidade na literatura ocidental, de 1946, problematizando a hipótese do mesmo no que diz respeito às relações entre literatura e realidade, mote através do qual se erige a citada obra. Partindo da exploração de alguns conceitos pertinentes à filosofia e à crítica literária do século $\mathrm{XX}$, mostraremos, através da exposição de algumas passagens de Mimesis, especialmente o capítulo sobre Dom Quixote, que há, por parte de Auerbach, uma tentativa abertamente conservadora de tentar resgatar uma tradição cultural que, para a Europa, se havia perdido com o advento da $1^{\mathrm{a}}$ e $2^{\mathrm{a}}$ Guerras Mundiais. Sua tentativa é aquela que tenta ainda ratificar uma ideia de literatura que exista a serviço da representação da realidade, algo que será posto em cheque já a partir do século XIX, e de forma mais radical ao longo do XX. Portanto, demonstraremos o quão dissonante se apresenta a hipótese de Auerbach, em sua cruzada para retomar uma certa ordem que a arte já havia muito renegara.

Palavras-chave: Erich Auerbach. Mimesis. Dom Quixote. Teoria Literária.

Logo no início de seu texto $O$ sabor do perspectivismo, o professor e crítico Raúl Antelo aponta para uma observação do romanista Ernst Robert Curtius que, de acordo com Antelo, "ao redigir este volume dedicado a Abi Warburg intitulado, de início, Idade Média latina e romance. Estudos sobre a tradição literária europeia, e que seria, finalmente, publicado como Europäische Literatur und lateinisches Mittelalter" (ANTELO, 2013, p. 222) descobrira "um poema espanhol do 1500 , que louvava um elenco de virtudes repartidas entre doze imperadores, de Augusto a Teodósio, que o convenceram da singular sobrevivência, na Península Ibérica, da tradição latina, como não se deu em nenhum outro lugar na Europa" ${ }^{\prime}$ (ANTELO, 2013, p. 222). O que buscava Curtius não dista daquilo que buscava outro filólogo, seu contemporâneo, Erich Auerbach, isto é, o resgate e a manutenção da tradição

\section{(i) $($ S.}

Esta obra está licenciada sob uma Licença Creative Commons.

\footnotetext{
* Mestrando em Literatura pela UFSC, cujo projeto consiste na exploração do escritor contemporâneo Antonio Vicente Seraphim Pietroforte em suas relações com as perversões do Sadismo e do Masoquismo, bem como a relação entre Literatura e Perversão num contexto mais amplo. E-mail: mradiego@gmail.com.

${ }^{1}$ Grifo nosso.
} 
cultural da Europa do pós-guerra. A Mimesis de Auerbach foi redigida entre 1942 e 1946, quando este se encontrava em seu exílio na Turquia; já o texto de Curtius data de 1948. O que ambos têm em comum, além do empreendimento acima citado, é que parecem ignorar, entre outras coisas, a existência de um personagem cuja importância foi fundamental para o período da Restauração inglesa, bem como para o resgate da cultura latina: John Dryden.

Nascido em uma obscura província pertencente à Northampton Shire, Dryden graduou-se em Cambridge a 1654, dali partindo de volta a Londres, onde conseguiu emprego como secretário de estado graças à influência de seu primo, Gilbert Pickering, lorde de Chamberlain. Já em 1660, celebrou a ascensão de Charles II ao trono, com o panegírico intitulado Astraea Redux, em que enaltecia o rei como restaurador da paz e da ordem na GrãBretanha. É de se imaginar que, com isso, Dryden acabou se tornando uma das maiores referências literárias de sua época. Posteriormente, escreveria ainda outros dois panegíricos dedicados a Charles II, To His Sacred Majesty: a panegyric on His coronation e To my Lord Chancellor, ambos datados de 1662. Mostrava-se, contudo, muito mais inclinado a escrever para a "nação" do que propriamente para a aristocracia, muito embora tivesse a obrigação de fazê-lo, algumas vezes por ano, por ser uma espécie de poeta laureado, tradição muito comum na Grécia e Roma antigas - Lucano e Estácio representam o poeta laureado romano por excelência, e não Virgílio, embora este também o fosse - e que foi recuperada pela Baixa Idade Média europeia. No ano seguinte, 1663, com a reabertura dos teatros, Dryden passou a dedicar-se à composição de peças. Seu primeiro trabalho, The Wild Gallant, aparece neste mesmo ano, sem muito sucesso ou repercussão. Porém em 1668 foi contratado para escrever três peças por ano para a Royal Company. Neste cargo escreveria suas duas obras-primas no teatro: Marriage à la mode, de 1672, e All for love, de 1678, destacando-se como o maior baluarte da comédia da Restauração na Inglaterra.

A contribuição de Dryden para a preservação da cultura latina - que parece ter passado despercebida a romanistas como Curtius e Auerbach -, no entanto, advém de outras fontes que não suas peças. Como tradutor de Virgílio, levou o poeta latino para o idioma inglês (muito embora Wordsworth critique severamente sua tradução da Eneida, afirmando que Dryden descreveria os objetos de maneira muito mais pobre que Virgílio); em seu ensaio Dramatick Poesie, em que defende avidamente as formas clássicas, como a epopeia, em relação, por exemplo, ao soneto (e há que se lembrar que não havia nem cem anos da morte de Shakespeare), ou na tradução e edição das Vidas, de Plutarco. Sua tradução de Virgílio foi considerada um marco para os leitores ingleses, e suas traduções de Ovídio, Homero e 
Bocaccio, reunidas num único volume sob o título de Fables ancient and modern o consolidariam como grande fomentador do resgate da cultura latina e como provedor, para a língua inglesa, dos textos clássicos, reverberando inclusive muito após a sua morte - exemplo disso é a admiração de John Keats, poeta do século XVIII, que confessadamente imita a forma das Fables em seu poema "Lamia". Seu pensamento em relação à própria língua inglesa era, se o considerarmos sob a ótica de alguém que escreve muito pouco tempo após Shakespeare, absolutamente inovador: defendia que as sentenças naquela língua jamais deveriam ser terminadas em preposições, uma vez que as sentenças latinas não podiam terminar de tal forma. De igual modo, foi grande defensor do verso heroico, em relação ao alexandrino. De vasta obra crítica, em que explicitamente defende a latinização da Inglaterra, seu destino talvez lhe tenha sido cruel ao fazê-lo ter vivido e escrito tão pouco tempo após Shakespeare; tivesse nascido antes que o bardo de Stratford-on-Avon, talvez o martelo da história lhe soasse mais suave.

Auerbach não menciona Dryden em sua Mimesis. Curtius, muito mais preocupado com a língua francesa, parece igualmente ignorá-lo.

A amnésia se nos apresenta como um problema frequente enfrentado por Auerbach. Da mesma forma que ignora Dryden, não publica, na primeira versão da Mimesis, o seu ensaio sobre Dom Quixote. Só o fará na edição mexicana do livro, em 1949. Acerca disso, não nos oferece esclarecimento algum em seu "Epílogo". Apenas bombardeia-nos com queixumes sobre suas dificuldades em escrever um livro que é ao mesmo tempo um projeto intelectual tão grandioso durante seu período no exílio, e divaga sobre o que poderia ter feito ou o que deixou de fazer, como neste trecho:

\footnotetext{
Cada capítulo trata de uma época; por vezes uma época relativamente curta, meio século, por vezes, também, uma época mais longa. Em meio a isso há frequentemente lacunas, isto é, épocas que não receberam nenhum tratamento, como é o caso da Idade Média, da qual demasiado pouco se conserva. Mais tarde também poderiam ter sido introduzidos capítulos sobre textos ingleses, alemães, espanhóis; teria tratado com prazer mais longamente do siglo de oro, e com muito prazer teria acrescentado um capítulo sobre o Realismo alemão do século XVII. Mas as dificuldades eram demasiado grandes; tratei de textos de três milênios e muito frequentemente tive de abandonar o âmbito que me é próprio, as literaturas românicas. Junta-se a isto, ainda, o fato de a pesquisa ter sido escrita durante a guerra, em Istambul. Aqui não há nenhuma biblioteca bem provida para estudos europeus; as comunicações internacionais estavam paralisadas; de tal forma que tive de renunciar a quase todas as publicações periódicas, à maioria das pesquisas mais recentes, e por vezes a edições críticas dos meus textos dignas de confiança. (AUERBACH, 1976, p. 502)
}

Podemos, de certa forma, ler a obra de Auerbach concedendo-lhe certa indulgência: tratava-se, como dito, de um projeto intelectual que, tivesse sido levado a cabo, talvez 
consumisse a vida de seu autor sem que viesse à luz. Não obstante, o que nos interessa neste breve estudo é ocupar-nos, justamente, das sombras.

Sombras que devem ser compreendidas da maneira descrita por Giorgio Agamben em seu $O$ que é o contemporâneo?, entenda-se, como aquilo que está à margem, que é, o mais das vezes, ignorado, arremessado a uma espécie de "lixeira da História", e que deve, segundo Agamben, ser recuperado pelo olhar do artista verdadeiramente contemporâneo ao tempo em que escreve. Realizando o movimento de leitura proposto pelo filósofo italiano, podemos começar minimamente a compreender o que está em jogo:

\begin{abstract}
O poeta - o contemporâneo - deve manter fixo o olhar no seu tempo. Mas o que vê quem vê o seu tempo, o sorriso demente do seu século? [...] contemporâneo é aquele que mantem fixo o olhar no seu tempo, para nele perceber não as luzes, mas o escuro. Todos os tempos são, para quem deles experimenta contemporaneidade, obscuros. Contemporâneo é, justamente, aquele que sabe ver essa obscuridade, que é capaz de escrever mergulhando a pena nas trevas do presente. [...] Contemporâneo é aquele que recebe em pleno rosto o facho de trevas que provém do seu tempo. (AGAMBEN, 2009, p. 62-64)
\end{abstract}

Agamben elabora sua hipótese a partir da análise do poema "O século", do poeta russo Osip Mandel'stam² ${ }^{2}$ Tomemos para nós esta premissa, a fim de tentar esquadrinhar, de certa forma, as sombras deixadas para trás, especialmente por Auerbach.

Muito embora a Mimesis seja um texto de inestimável valor - equivalente ou superior a muitos cursos de literatura -, é inegável que nos causa certo estranhamento, especialmente se considerarmos a época em que foi escrito, figurando como uma espécie de reação humanista ao pós-guerra, uma tentativa de por certa ordem ao caos que se seguiu à ruína europeia. Encontra-se em clara relação de tensão com um debate que se iniciou no século XIX, sobre a insustentabilidade de uma arte que se apresentasse como "representação". Da mesma forma, pode ser vista como uma espécie de reação a uma atitude de vanguarda mais radical - entenda-se Marcel Duchamp e o André Breton da segunda corrente surrealista, ou mesmo o expediente (nada modesto) da revista Acéphale, e sua prerrogativa de um resgate de Nietzsche, de quem se apropriara o nazismo. É interessante contrapor ao desespero humanista de um resgate logocêntrico, por parte de Auerbach e Curtius, as premissas de Georges Bataille, já no primeiro número da citada revista. Diz Bataille:

É tempo de abandonar os civilizados e sua $l u z^{3}$. É tarde demais para querer ser razoável e instruído - o que levou a uma vida sem atrativo. Secretamente, ou não, é necessário devir totalmente outros ou cessar de ser. [...] O homem escapou da sua

\footnotetext{
${ }^{2}$ Traduzido, no Brasil, sob o título de "A era". In: CAMPOS, Haroldo de. Poesia russa moderna. São Paulo, Brasiliense, 1987.

${ }^{3}$ Grifo nosso.
} 
cabeça como o condenado da prisão. Encontrou, para além dele mesmo, não Deus, que é a proibição do crime, mas um ser que ignora a proibição. (BATAILLE, 2013, p. 1)

Aqui podemos perceber a preocupação de Bataille em se afastar da "luz" civilizatória, o que vai ao encontro da proposta mesma da revista que, desde seu título, nos informa sobre a derrocada do iluminismo na Modernidade, sobretudo a partir de fins do século XIX e ao longo do XX. Ora, podemos atestar com certa segurança a problemática tarefa empreendida por Auerbach, a saber: como reorganizar e reestruturar um conhecimento e uma tradição praticamente aniquiladas pela experiência da guerra? Não obstante, é a isto que se propõe Auerbach.

No Brasil, em fevereiro de 1922, a Semana de Arte Moderna alteraria irremediavelmente os rumos do pensamento estético nacional. Neste mesmo ano, em Frankfurt, outro evento ocorreria que, igualmente, alavancaria uma discussão que se estende por todo o século XX. O jovem marxista Felix Weil organiza, com a esperança de agregar diferentes linhas do marxismo alemão, um simpósio de uma semana, ao qual assistiriam figuras como György Luckács, Karl Korsch, Karl August Wittfogel e Friedrich Pollock. Com o sucesso do evento, Weil começa a financiar salários para colaboradores, bem como a construção de um instituto, o Instituto Para a Pesquisa Social - obra finalizada em 1923 e inaugurada por Carl Grünberg - que se configurava como um anexo à Universidade de Frankfurt. Estava dado o ponto de partida para aquilo que, posteriormente, se denominou "Escola de Frankfurt". Com o advento da guerra, em 1933, o Instituto deixa a Alemanha e instala-se em Genebra; posteriormente, em 1935, muda-se para Nova Iorque, onde se afilia à Universidade de Columbia.

Não é preciso ilustrar aqui a importância histórica da Escola. O que nos interessa, neste momento, são os dois principais mananciais teóricos que dali emergiram, encabeçados, de um lado, por Walter Benjamin (1989) - que não era, para todos os efeitos, um integrante formal da Escola, e sim um colaborador - e, de outro, por Theodor Adorno e Max Horkheimer (1985), em sua relação dicotômica com o pensamento de Auerbach. Se Benjamin foi pioneiro em escrever sobre a importância de se atentar para o que encontra-se à margem, nas "sombras", e Adorno e Horkheimer desenvolveram o argumento de uma autonomia da arte, ou seja, que estavam lidando com o que vivenciavam, e, pensando o século XX de acordo com as ferramentas de que dispunham, o projeto de Auerbach e Curtius parecia ter a ambição de reconstruir o edifício implodido pela guerra. O que não parece de todo algo impensável, uma vez que, se voltarmos à Agamben, este nos dirá que “À filologia foi sempre 
confiada a tarefa de garantir a genuinidade e a continuidade da tradição cultural" (AGAMBEN, 2005, p. 164).

Não obstante, o debate que perpassa o século XX, fomentado por Warburg e que trata da importância das imagens, começa a sutilmente engendrar o tipo de pensamento que se verificará na obra de, por exemplo, Benjamin: o que fazer com o que resta, com o que não foi lido ou, em última instância, não pôde ser lido? Curtius que, de acordo com Raúl Antelo, “também lutava contra o abandono internacional da tradição alemã” (ANTELO, 2013, p. 223), posiciona-se de modo menos conservador que Auerbach, ao constatar, "com Goethe, que a literatura não passa de "fragmentos de fragmentos"” (ANTELO, 2013, p. 223). Problemática bastante presente nos debates sobre os fins da literatura (qualquer duplo sentido aqui não deve ser interpretado como mera coincidência), especialmente a partir da segunda metade do século passado, e que nos situa, como leitores, no cerne do processo de construção textual. Se nada nos chega, por assim dizer, completo, se não conseguimos o acesso a um texto primordial, uma totalidade do texto, nossa tarefa passa a ser, então, a de lidar com a parte deste texto que nos cabe, que possuímos, para a partir daí explorá-lo e verter dele toda a sua potência. E a literatura, assim vista, configura-se como potência infinita, como constante prática de releitura. Benjamin, em seu ensaio sobre Baudelaire, aponta para a importância, com a ascensão das metrópoles e do modo de produção industrial, de figuras como o boêmio, o conspirador, o bricoleur. O próprio estilo de escrita do filósofo alemão é aquele do bricoleur, um movimento fragmentário, não linear, que pouco a pouco abre caminho para a presença do poeta lírico sobre quem Benjamin nos oferece um itinerário poético. Também é através da linguagem transformada em potência, a literatura, que nos confrontamos com o incômodo, o inenarrável vazio de nós mesmos. Pode-se afirmar que a literatura é perigosa. Ela sempre nos conduzirá a este "fim do mundo" a que se referia Leo Spitzer - talvez o menos conservador dos filólogos até agora citados - quando confrontado pelo Pantagruel de Rabelais, este abismo de onde nenhuma luz provém. E é a partir dali que devemos observar, por exemplo, o cavaleiro da triste figura, Dom Quixote de La Mancha.

Tomemos o ensaio de Auerbach sobre o Quixote. O projeto da Mimesis consiste em resgatar, de certa forma, a noção de representação da realidade na literatura ocidental, como seu título mesmo nos anuncia. E o respaldo para isso encontra Auerbach no conceito de um "realismo figural", que deriva da noção de "figura", sobre a qual nos apresenta referencial teórico em livro de mesmo título, e que em Mimesis é aplicada de forma mais prática, de acordo com o método por ele empregado: analisar as relações entre a literatura e o conceito de 
realidade - muito embora não defina este último com precisão ao longo da obra - através da leitura de trechos de romances clássicos do Ocidente. Sua obra flutua entre dois eixos: este do "realismo figural", acima citado, e o de uma espécie de separação, proposta por Auerbach, entre um "alto realismo" e um "baixo realismo". A diferença entre estes últimos, de acordo com o autor, seria que o "alto realismo" representaria o sublime e seria um estilo das classes mais elevadas, ao passo em que o "baixo realismo" se configuraria como a representação literária das classes mais baixas. No rastro de Aristóteles (2005), o "alto realismo" auerbachiano pode ser claramente identificado com a Tragédia, ao passo em que como "baixo realismo" se tomaria a Comédia. E é justamente por conta desta distinção de estilos, herdada do filósofo grego e aplicada em sua análise, que Auerbach começa a defrontar-se com sérios problemas de ordem analítica, uma vez que, se para os textos da Antiguidade Clássica, Aristóteles não oferece concessões, o filólogo alemão é obrigado a fazê-lo, protagonizando momentos de franca desorientação em relação ao seu objeto de análise. Possivelmente os casos em que isto melhor se verifica sejam suas incursões em Dom Quixote de Miguel de Cervantes (2004) e To the lighthouse, de Virginia Woolf. Aqui nos deteremos brevemente na exploração de seu capítulo sobre Dom Quixote.

O ponto de partida do ensaio é um trecho do capítulo 10, da segunda parte do romance de Cervantes: Sancho Pança é enviado por Quixote a Toboso, com o intuito de encontrar Dulcinéia e avisá-la da visita de Quixote e, embaraçado por não encontrá-la, engendra um plano para enganar seu amo: espera por algum tempo na vila, até ver passarem três camponesas montadas em três burros. Retorna então a seu mestre e anuncia-lhe que ali vem Dulcinéia, acompanhada de duas damas. Quixote, tão acostumado a transfigurar em ilusão a sua realidade, no momento em que a ilusão do embuste lhe é apresentada, não consegue senão extrair da cena a sua realidade, isto é, três camponesas montadas em três burros. Dali decorre um cômico episódio entre Quixote e as camponesas. Sobre este episódio nos informa Auerbach:

Entre os muitos episódios que representam o embate entre a ilusão de Dom Quixote com uma realidade quotidiana e oposta à ilusão, este ocupa uma posição especial. Em primeiro lugar porque se trata da própria Dulcinéia, a ideal e incomparável senhora do seu coração; é o auge da sua ilusão e da sua desilusão, e, mesmo que também neste caso encontre uma saída para salvar a ilusão, esta saída (Dulcinéia está encantada) é tão dificilmente suportável que dali em diante todos os seus pensamentos estão dirigidos para a meta da sua salvação e da quebra do encantamento; a noção ou o pressentimento de que isto nunca será conseguido é, nos últimos capítulos do livro, a preparação imediata da sua doença, da libertação da sua ilusão e da sua morte. Depois, esta cena distingue-se pelo fato de que nela, pela primeira vez, os papéis estão trocados: até ali era Dom Quixote que compreendia espontaneamente e transformava as aparições da vida quotidiana com que se 
deparava, segundo o sentido dos romances de cavalaria, enquanto Sancho em geral duvidava ou retorquia ou tentava evitar as absurdas ações de seu amo; agora é o contrário, Sancho improvisa uma cena de romance, enquanto que a capacidade de Dom Quixote de transformar os acontecimentos segundo a sua ilusão falha diante da crua vulgaridade do aspecto das lavradoras. Tudo isto parece ser altamente significativo; tal como nós o apresentamos aqui (propositadamente), parece triste, amargo e quase trágico. (AUERBACH, 1976, p. 303)

"Quase trágico", infere Auerbach. Este "quase” pode ser mais bem compreendido se confrontarmos o ensaio sobre Dom Quixote com aquele sobre Hamlet, obra que, esta sim, é trágica, de acordo com o autor. Ao cotejarmos ambos os ensaios, podemos perceber em Auerbach um esforço no sentido de legitimar em Hamlet uma "loucura séria" e em Quixote uma loucura lúdica, espirituosa. Reduz, em última instância, a obra de Cervantes a um emaranhado de galhofas, como expressa em passagens como esta:

Encontra-se, pois, muito pouco de problemático ou trágico no livro de Cervantes embora seja uma das obras-primas de uma época, durante a qual se formaram a problemática e a tragédia europeias. A doidice de Dom Quixote nada revela disto; o livro todo é um jogo, no qual a loucura se torna ridícula quando exposta a uma realidade bem fundamentada. (AUERBACH, 1976, p. 310)

Ou esta, na qual conseguimos visualizar a evidente desorientação de Auerbach:

Assim como Deus faz o sol brilhar e a chuva cair sobre justos e injustos, assim também a loucura de Dom Quixote ilumina tudo o que encontra no seu caminho com alegre indiferença, e deixa tudo em alegre confusão. (AUERBACH, 1976, p. 314)

Ou ainda esta, com a qual arremata seu ensaio, após haver definido algo como uma função para a loucura de Quixote, que colore com temas como a fé na Graça e algum remorso advindo da Queda:

No que se refere ao mundo terreno em geral, somos todos pecadores; Deus providenciará para que o malvado seja castigado e o bom, premiado. Aqui, na terra a ordem do que não pode ser abrangido com os olhos está no jogo: por mais difíceis de abranger e de julgar que sejam os fenômenos diante do doido cavaleiro da Mancha, eles se convertem numa dança de roda, de alegre e divertida confusão. Esta é, segundo me parece, a função da loucura de Dom Quixote. Quando o tema - a saída do fidalgo doido que quer tornar a realidade o ideal do caballero andante começou a inflamar a força imaginativa de Cervantes, ele também teve uma visão de como a realidade contemporânea, confrontada com tal loucura, deveria ser representada: e ele gostou deste quadro, tanto pela sua multiplicidade quanto pela hilaridade neutra que a loucura espalha sobre tudo o que encontra. $\mathrm{O}$ fato de se tratar de uma loucura heróica e idealista que deixa espaço para a sabedoria e a humanidade, certamente não lhe agradou menos. Mas considerar esta loucura simbólica ou tragicamente, isto eu acho um ato de violência. É possível introduzi-lo através da interpretação, mas não está no texto. (AUERBACH, 1976, p. 320)

Sobre esta última passagem poderíamos nos debruçar por horas. Este é talvez o único momento de Mimesis - caberia uma releitura extensiva da obra para se ter absoluta certeza - 
em que o eu de Auerbach se mostra, ainda que fugidiamente. E é, para todos os efeitos, um eu que duvida, que acha, não está seguro do que afirma. Isto transparece claramente, tanto nos trechos acima citados, como ao longo de todo o ensaio sobre o Quixote; é também algo que se repetirá posteriormente, já ao final do livro, na análise do romance de Woolf. A impressão que temos é a de que Auerbach não sabe muito bem sob qual viés de seu escopo teórico explorar Dom Quixote - até então tudo correra bem em sua análise de outras obras, agora ele hesita, se coloca no texto, apela para certa religiosidade que, a seu ver, compartilha com Cervantes, alguém que, de acordo com ele, "nunca teria pensado que o estilo de um romance, e mesmo do melhor de todos, pudesse desvendar a ordem universal (AUERBACH, 1976, p. 319)". Fala, inclusive, de uma visão de Cervantes, e é impossível não delegar ao termo, sob tais circunstâncias, seu caráter religioso. Se até este momento a Mimesis devia muito de sua hipótese a Aristóteles, neste ensaio sobre Dom Quixote, Auerbach nos mostra ser igualmente tributário de Miguel de Unamuno, em cuja Vida de Don Quijote y Sancho se pôde primeiro observar esta suposta vocação visionária de Cervantes, a saber, que a obra Dom Quixote possui significados absolutamente transcendentes e que o ingênuo Cervantes não os poderia ter captado ou mesmo dimensionado sua imortalidade. A este respeito, cabe resgatar um texto de Francisco Ayala, escrito em 1947 - ou seja, um ano após a $1^{\text {a }}$ edição de Mimesis, e dois antes da inclusão do ensaio sobre Dom Quixote - em que este se posiciona de forma radicalmente contrária às premissas de Unamuno (2000) e de seus sucessores. Nas palavras de Ayala:

Así se explica que, en los primeros años del passado siglo, se revolviera Unamuno
contra ese mundo cervantesco, y contra el proprio Cervantes, en uma rabiosa,
integral afirmación del Quijote, de la esencia poética, frente al accidente en que se
manifesta. [...] La vulgarizada tesis según la cual el autor del Quijote habría sido um
pobre hombre, genio inconsciente sin capacidad para percatarse de la especie de
criatura que engendraba, se funda - a no dudarlo - en la intuición del significado
transcendente alojado em la obra de Cervantes. Oscuramente, se percibió siempre
ahí la presencia de un algo descomunal, secreto, insondable, que falta en la gran
turbamulta de las figuras inventadas por la imaginación literaria, y que tampoco se
encuentra en las demás producciones del proprio Cervantes [...] Y como lo
portentoso suele identificarse com lo sagrado, y como el mito pertenece en verdad a
la órbita religiosa, se ha propendido desde el comienzo a adorar en el Quijote una
especie de misterio - con su culto, sus exégetas, interpretaciones esotéricas,
ministros y sectarios -, atribuyendo a su creación - o, mejor, revelación -
circunstancias de milagro, entre ellas la que da esa revelación por cumplida a través
de un inocente, ajeno al valor sublime que le era confiado. (AYALA, 2004, p.
XXXIII-XXXIV)

Buscar em Cervantes uma identificação com o sagrado, uma iluminação que the garantisse a permanência em nossos manuais de literatura, é algo que, de certa forma, desviou as atenções para o que realmente está em jogo, a potência da obra, e, sendo Unamuno o 
representante máximo da chamada "geração de 98" espanhola, é de se esperar que o tipo de abordagem por ele executada, em relação ao Quixote, teria muita repercussão entre contemporâneos e futuros escritores e críticos. O que, de acordo com Ayala - que dedicou algo como 40 anos de sua vida a estudar Dom Quixote, mas parece encontrar-se em posição misteriosamente subterrânea em relação às discussões da obra - representou uma espécie de retrocesso nos estudos e mesmo na exploração de possibilidades da narrativa de Cervantes.

Afastando-nos do vértice auerbachiano, torna-se evidente que Dom Quixote não possui nada do inocente espiritualismo proposto pelo filólogo alemão. Trata-se de uma narrativa que busca, em pleno século XVII, problematizar o poder da literatura enquanto transformadora da vida e da realidade, realidade esta que Auerbach está tão preocupado em legitimar. Acima dizíamos que a literatura é perigosa. E ela o é, justamente, porque é através dela que se pode criar mundos, cujo teor de real é tão ou mais consistente do que o daquilo que se convencionou chamar "realidade". Para confirmar nosso apontamento, basta questionar-se acerca da rapidez com que todo e qualquer regime autocrático busca queimar determinados livros ou proibir sua veiculação. Igualmente o corrobora a onda de suicídios de jovens alemães do século XIX, após a leitura de Os sofrimentos do jovem Werther, de Goethe. No Brasil, durante as recentes manifestações de junho/julho de 2013, policiais prenderam um manifestante e, dentre as supostas provas de seus atos de vandalismo coletadas, encontravamse os dois volumes do livro intitulado Mate-me por favor: uma história sem censura do punk, de Legs McNeil e Gillian McCain (2004). A própria literatura nos fornece exemplos tais, seja através de obras como Fahrenheit 451, de Ray Bradbury (2004), seja através de História universal da destruição dos livros: das tábuas sumérias à guerra do Iraque, do venezuelano Fernando Baéz (2006).

No romance Triste fim de Policarpo Quaresma, Lima Barreto (1989) também bebe da fonte do quixotismo, e nos apresenta um personagem que, a exemplo de Dom Quixote, transfigura em realidade a paixão pela literatura. Quanto a isto, e ainda para reforçar nossa ideia de um mundo, por assim dizer, contaminado pela literatura, é interessante notar que aqueles que encontram-se ao redor de ambas as personagens - tanto Quaresma como Quixote - tentam demovê-los de seus ideais através da renúncia à biblioteca, que é vista em ambas as narrativas como o gatilho disparador da loucura de seus personagens. Em Dom Quixote, o ato de corte em relação à literatura se dá no capítulo VI da primeira parte do romance, intitulado "Del donoso y grande escrutinio que el cura y el barbero hicieron em la librería de nuestro ingenioso hidalgo"; e em Triste fim de Policarpo Quaresma, no capítulo "A notícia de 
Genelício". Há, em ambas as passagens, o julgamento em relação à literatura, prático em Dom Quixote, ideológico em Policarpo Quaresma.

Finalmente, Borges e Kafka não seriam dois dos piores exemplos de autores que, a todo o momento, parecem pisar na noção de realidade tão cultuada por nós, ocidentais, e defendida por Auerbach. A premissa de reconstruir mitos parece presente em suas obras de forma exemplar - o que se pode observar em muitos outros escritores; contudo, ironicamente, somos obrigados a realizar um movimento similar ao de Auerbach, e eleger, nós mesmos, nossos próprios cânones. Ao passo em que Borges atesta em sua obra a tensão entre o real da literatura e o real do mundo, como nesta Parábola de Cervantes y del Quijote,

Harto de su tierra de España, un viejo soldado del rey buscó solaz en las vastas geografias de Ariosto, en aquel valle de la luna donde está el tiempo que malgastan los sueños y en el ídolo de oro de Mahoma que robó Montalbán. En mansa burla de sí mismo, ideó un hombre crédulo que, perturbado por la lectura de maravillas, dio en buscar proezas y encantamientos en lugares prosaicos que se llamaban El Toboso y Montiel. Vencido por la realidad, por España, Don Quijote murió en su aldea natal hacia 1614. Poco tiempo lo sobrevivió Miguel de Cervantes. Para los dos, para el soñador y el soñado, toda ésa trama fue la oposición de dos mundos: el mundo irreal de los libros de caballerías, el mundo cotidiano y común del siglo XVII. No sospecharon que los años acabarían por limar la discordia, no sospecharon que la Mancha y Montiel y la magra figura del caballero serían, para el porvenir, no menos poéticas que las etapas de Simbad o que las vastas geografías de Ariosto. Porque en el principio de la literatura está el mito, y asimismo en el fin. (BORGES, 1974, p. 799)

Kafka, sombriamente, como lhe é característico, reelabora a problemática da leitura no texto cervantino, neste $A$ verdade sobre Sancho Pança:

\begin{abstract}
Sancho Pança, que por sinal nunca se vangloriou disso, no curso dos anos conseguiu, oferecendo-lhe inúmeros romances de cavalaria e de salteadores nas horas do anoitecer e da noite, afastar de si o seu demônio - a quem mais tarde deu o nome de D. Quixote - de tal maneira que este, fora de controle, realizou os atos mais loucos, os quais no entanto, por falta de um objeto predeterminado - que deveria ser precisamente Sancho Pança -, não prejudicaram ninguém. Sancho Pança, um homem livre, acompanhou imperturbável, talvez por um certo senso de responsabilidade, D. Quixote nas suas sortidas, retirando delas um grande e proveitoso divertimento até o fim de seus dias. (KAFKA, 2002, p. 103)
\end{abstract}

A literatura, o texto, exige de nós que sejamos tributários de sua potência. Ao longo dos séculos, ela nos tem mostrado que dificilmente se deixa apanhar, esquadrinhar. Assim, as tentativas de críticos como Auerbach, ou de seu discípulo Edward Said - que relembra Auerbach com saudosismo e afirma que a erudição acabou - ou, se quisermos lançar um breve olhar para nosso próprio quintal, Roberto Schwarz ou Leyla Perrone-Moisés - que, de forma semelhante a Said, afirma que a literatura acabou - nos mostram que, se por um lado, há uma certa crítica empenhada em manter cânones e eleger pais para a literatura, há, por 
outro, uma crítica que se especializou em buscar justamente o que está à margem - vide Foulcault, Derrida e, mais recentemente, Josefina Ludmer, apenas para citar alguns -, que se adequa às mudanças e demandas históricas pelas quais a literatura é atravessada e que, ao invés de lamentar-se pela época de ouro que foi e já não volta, está muito mais interessada em propor discussões e explorar a literatura contemporaneamente ao que nela se verifica, isto é, de acordo com os movimentos realizados por algo que não é, de forma alguma, estático ou cristalizado pelo olhar ambíguo da história.

\section{Referências}

ADORNO, Theodor; HORKHEIMER, Max. Dialética do esclarecimento. Tradução de Guido Antonio de Almeida. Rio de Janeiro: Jorge Zahar, 1985.

AGAMBEN, Giorgio. Infância e história: destruição da experiência e origem da história. Tradução de Henrique Búrigo. Belo Horizonte: UFMG, 2005.

. O que é o contemporâneo? e outros ensaios. Tradução de Vinicius Nicastro Honesko.

Chapecó: Argos, 2009.

ANTELO, Raúl. O sabor do perspectivismo. Revista Landa, Florianópolis, v. 1, n. 2, p. 221 $250,2013$.

ARISTÓTELES; HORÁCIO; LONGINO. A poética clássica. Tradução de Jaime Bruna. São Paulo: Cultrix, 2005.

AUERBACH, Erich. Mimesis: a representação da realidade na literatura ocidental. Tradução de Editorial Perspectiva. São Paulo: Perspectiva, 1976.

AYALA, Francisco. La invención del Quijote. In: CERVANTES, M. de. Don Quijote de la Mancha. São Paulo: Alfaguara, 2004. Edición del VI centenario.

BAÉZ, Fernando. História universal da destruição dos livros: das tábuas sumérias à guerra do Iraque. Tradução de Léo Schlafman. Rio de Janeiro: Ediouro, 2006.

BARRETO, Lima. Triste fim de Policarpo Quaresma. Rio de Janeiro: Garnier, 1989.

BATAILLE, Georges. A conjuração sagrada. In: BATTAILE, G.; KLOSSOWSKI, P.; MASSON, A. Acéphale vol. 1. Tradução de Fernando Scheibe. Florianópolis: Cultura e Barbárie, 2013.

BENJAMIN, Walter. Charles Baudelaire: um lírico no auge do capitalismo. Tradução de José Martins Barbosa, Hemerson Alves Baptista. São Paulo: Brasiliense, 1989 (Obras escolhidas, v. 3).

BORGES, Jorge Luis. Obras completas. Buenos Aires: Emecé Editores, 1974. v. 1.

BRADBURY, Ray. Fahrenheit 451. Nova Iorque: HarperCollins Publishers, 2004.

CAMPOS, Haroldo de. Poesia moderna russa. São Paulo: Brasiliense, 1987. 
CERVANTES, Miguel de. Don Quijote de la mancha. São Paulo: Alfaguara, 2004. Edición del IV centenario.

HOPKINS, David. John Dryden. Londres: Northcote House Publishers, 2004.

KAFKA, Franz. Narrativas do espólio. Tradução de Modesto Carone. São Paulo: Companhia das Letras, 2002.

McCAIN, Gillian; McNEIL, Legs. Mate-me por favor: uma história sem censura do punk. Tradução de Lúcia Brito. Porto Alegre: L\&PM, 2004. v. 1 e 2.

UNAMUNO, Miguel de. Vida de Don Quijote y Sancho. Madrid: Alianza editorial, 2000.

[Recebido em janeiro de 2014 e aceito para publicação em abril de 2014]

\section{Auerbach's choices: a matter of reality}

Abstract: This paper seeks to discuss some of the concepts proposed by German philologist Erich Auerbach, focusing on his work Mimesis: the representation of reality in Western literature, from 1946, problematizing his hypothesis in what concerns to the relations between literature and reality, the motto through which the quoted work is constructed. Starting with the exploration of some relevant concepts to philosophy and literary critic of $20^{\text {th }}$ century, we will show, through exposition of some parts of Mimesis, especially the chapter about Don Quixote, that there is, by Auerbach, an openly conservative attempt to rescue a cultural tradition which, to Europe, had been lost since the advent of the $1^{\text {st }}$ and $2^{\text {nd }}$ World Wars. His attempt is that which still tries to ratify the idea of a literature which exists to the duty of representation of reality, something that will be put to check from the $19^{\text {th }}$ century, and more radically in the $20^{\text {th }}$. Thus, we will demonstrate how dissonant is Auerbach's hypothesis, in his crusade to retake a certain order that art itself had disowned a long time ago.

Keywords: Erich Auerbach. Mimesis. Don Quixote. Theory of literature.

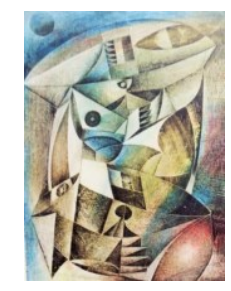

